\title{
English Language Competence of Secretary Students through Report Writing: Corpus Based Study
}

\author{
Elvi Citraresmana \\ elvi.citraresmana@unpad.ac.id \\ Universitas Padjadjaran
}

\begin{abstract}
This research is entitled "Observing English Language Competence of Secretary Students through Report Writing: Corpus Based Study". The main purpose of this research is to analyze the language competence of the Secretary Students in one of popular Academy Secretary in Bandung. The Language competence is something important for students in order to understand what they say or what they write. Every language competence implies meanings. Unfortunately not all students know how to understand the meanings through language. What they have in their minds that they have to write in good grammatical patterns. They keep busy memorizing the grammatical patterns without knowing the purpose of those patterns. This research uses the Corpus Linguistics method. This newly method is quite promising and interesting to implement in this research. The definition of Corpus Linguistics is used the theories which was proposed by McEnery and Wilson (1996, 2001), Sinclair et al. (2004), Lindquist (2009), McEnery and Hardie (2012). In collecting data, the writer determined the keywords then found out the implementation of those words into their writing. There are 7 key words which are used by the students frequently. The result of this research shows that the students mostly use the elements of grammar such as determiner of "the" and "a", preposition such as "in", "on", "about"; yet, they rarely implement those 7 keywords with any variation. Lack of using variation collocation to the keywords causing the ambiguity to the readers.
\end{abstract}

Key Words: corpus linguistics, language competence, secretary, grammar, pattern

\section{Introduction}

Mastering language or languages is an absolute prerequisite for a candidate of secretary. The secretary candidate is supposed to have a good communication skill. This requisition is needed considering that a secretary is going to do a lot of interactions with various sides, such as colleagues, managers, and other profession. The aim of communication is sending the message or messages, giving the opinion, or sharing the information. Those aims of communication can be delivered whether by oral or written.

Researcher analyzes report writing of secretary students in one of Academy Secretary in Bandung which is very popular. This Report Writing subject was conducted by students batch 2015/2016, in the class during academic year of 2016/2017. In this lecture, the students were given the exercises of writing various report. One of the report is in the form of graph, pie chart, and bar chart. They were instructed to read those graph, pie chart, and bar chart, then they were asked to deliver their reading result by writing it into the report.

Writing is one of the language skills. Through writing, we can observe one's language ability. It is believed that writing is a kind of reflection of the writer's cognition, since that written will represent the writer him/herself. Unfortunately, there were some weaknesses appeared in the student's writing results. Those weaknesses happened due to lack of confidence in sharing their ideas into writing, the limitation of English grammar comprehending, not to mention the influence of mother native language and also Bahasa Indonesia as our nation language. Those weaknesses occurred in their writing using English but the structure is in Bahasa.

From that case, it can be understood that we have to encourage our students to the needs of language competence and language performance. English language competence has already been taught started from Junior High School until Senior High School, nowadays, mostly English has been taught started in Elementary School. In this article, the researcher discusses English language competence of college students especially secretary students using corpus method.

\section{Theory and Method}

This research focuses on analyzing the writing results of Secretary students in Bandung especially in Report Writing subject conducted in the class, those writing results were collected as the data source. The keyword is needed in order to collect the data. In this research, the researcher used the keyword that frequently occured in the 
students writing result. Those frequent words derived from the Antconc software after all data were set into plain text.

This research used Corpus Linguistics and English grammar structure. Concerning of Corpus Linguistics, this research used the frequency of words appeared in their writing result; and concerning of Language Competence, this research used English grammar structure as the standard of understanding. As the keyword, this research used the word of show, give, inform, increase, decrease, rise, and fall. Those words were used frequently by students in order to describe the graph.

On the understanding of Corpus Linguistics, the researcher used the theory proposed by McEnery and Wilson (2001), Lindquist (2009), McEnery and Hardie (2012) among others. Corpus Linguistics is the study of language as expressed in corpora (samples) of "real world" text (https://en.wikipedia.org/wiki/Corpus_linguistics). Kennedy (1998:1) stated that Corpus Linguistics is a kind of research method which is designed to analyze the corpora. According to McEnery and Wilson (1996:1) Corpus Linguistics also more often analyze the methodology than analyze the language aspects which needs the explanation and description (see dissertation of Citraresmana, 2014: 13).

On the understanding of language competence, the researcher refers to english grammar structure, as mentioned by Biber, et.al. (1999). Biber (1999) suggested that word order in English was used as the grammatical sign which was arranged into four ways as follows.

(1) The element of clause is arranging in a preferred order in relation to each other; such as the subject occurs before the verb, the verb occurs before the complements: SV, SVA, SVPs, SVOd, SVOp, SVOiOd, SVOdOp, SVOdPo, SVOdA.

(2) Independent interrogative clauses are signalled through subject-operator inversion. This Subject-Operator inversion is an obligation and should be replaced in the beginning of sentence especially when using the word never.

(3) All clause elements realized by $w h$-words are regularly placed in initial position. Whether it is in the form of independent clause, interrogative, exclamative, or dependent noun, and relative clause.

(4) Phrases are normally continuous, this is what is called as principle of contact. But in certain cases there is the principle of contact which is not accord with the order. This happens due to the needs of cohesion, emphasizing, or any other sytilistic effects.

(Biber, et.al., 1999:899)

Those grammatical principle to the word order used as the reference of analysis. In order to analyze meaning and the usage of the verb, this research used Wordnet. Wordnet is a software used to find out the word, meaning, and the usage.

Corpus Linguistics mainly discusses the method of research. In this research, the researcher refered to the understanding of Palmerian (1933). Palmer (1933) proposed adjacent collocations using descriptive statistics. The data were collected through the frequency of words occured from the students writing. This collocations in window is understood as collocates. Collocates is the collocation word appeared together with keyword. Both appearances resulted collocation in window. Spans of window are varied, in which the collocates appeared in left or right of node words. This understanding is accord with Sinclair, et.al. (2014) (in Lindquist, 2009: 73 \& 78). This adjacent collocation is similar to linguistic structural with descriptive statistic (the appearance of frequent collocation). In this research, data were collected and formed into plain text, then applied into Antconc software. The verbs give, show, inform, increase, decrease, rise, and fall were used as the keyword, considering that those verbs commonly used when the graphs were described. So, from those verbs, the researcher analyzed the collocates appeared with the verbs and then will come to the conclusion of the language competence of secretary students in Bandung.

\section{Findings and Discussion}

There were 53 texts derived from three paralel classes. From those 53 texts there were 5457 token appeared in the word list resulted from the data collection of student's report writing, as described in the picture below. 


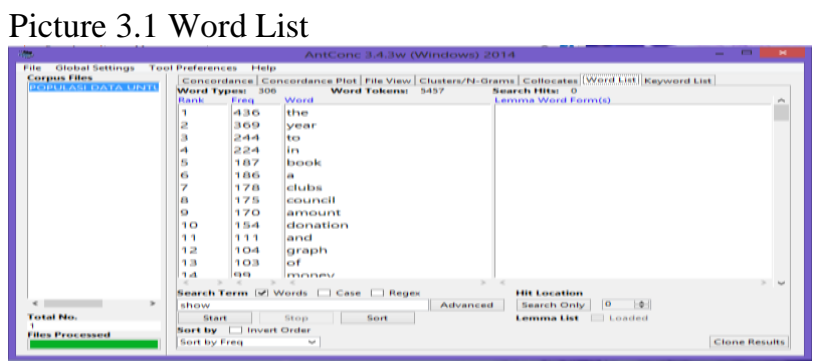

From the picture 3.1 above, it can be seen that determiner 'the' appeared as much as 436 times. Those typical appearances also happened when the researcher made a test by typing other verbs such as show, give, inform, increase, decrease, rise, and fall. Determiner 'the' is the most frequent word used by the students. Those students prefered to use closed class instead of using other words (open class) to show their language performance. Since the topic that was given about the graph, the 2 nd place that appeared from their writing result was 'year'. This word 'year' appeared as much as 369 times from the total of word occurences. Then it was followed by preposition 'to' and 'in' appeared as much as 244 times and 224 times respectively. These findings are about to discuss in the following.

\section{The Collocates of the Verb 'Show'} below.

This session is about to discuss the collocates that appeared with the verb 'show' as described in the picture

Picture 3.2 Clusters/N-grams of the verb 'show'

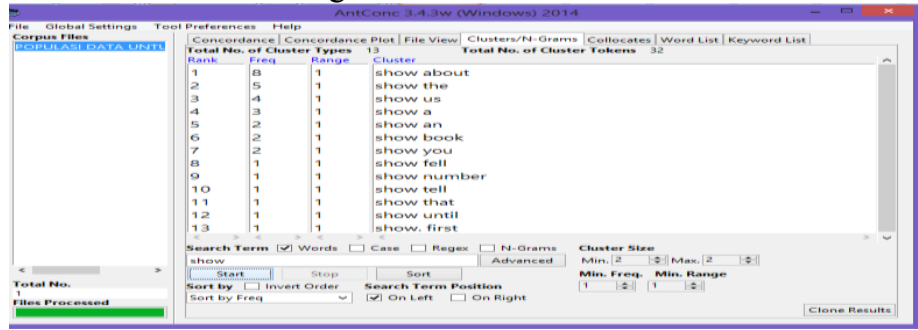

The picture 3.2 above shows that as much as 8 times, the students used preposition 'about'; and as much as 5 times, the students used determiner 'the'. Below 5 times, they used possessive pronoun 'us' ( 4 times), determiner 'a' and 'an' were used about 3 and 2 times. The word 'book' and 'you' showed about 2 times. The rest is not too frequent used by the students as much as 1 times (see the pictures).

From the cluster/N-grams above, it is understood that the students used determiner 'the' frequently appeared together with the verb 'show' and then it was followed by preposition 'to' and 'in'; determiner 'a'; conjunction 'and'; and preposition 'of'.

The verb 'show' in Oxford Dictionary Thesaurus and Wordpower Guide (2001: 833) means (1) be or make visible; (2) offer for inspection of viewing; (3) present an image of; (4) lead or guide; (5) treat (someone) in a particular way; (6) be evidence of; prove; (7) cause (someone) to understand something by explaining it or doing it oneself. Through the meaning derived from the dictionary above it can be concluded that the verb show in the data means be or make visible; offer for inspection of viewing; be evidence of.

In Biber, et.al. (1999:701), the verb 'show' is a type of communication verb which is appeared grammaticaly in a structure of "verb + NP + to-clause (or be verb -ed + to clause)". Based on the dictionary and grammatical structure of Biber, et.al., it can be understood that the structure of the verb 'show' is as follows.

(1) show [someoneNP] (to see something-to clause)]

(2) show [a presentationNP]

(3) [S (is shown-be verb -ed) (to everyone-to clause)]

Based on the understanding proposed by Biber, et.al., (1999), there were only 4 and 2 students who used the structure of "show somone to see something" as in "show us" and "show you" (see picture 3.2). This means that only a few students (6 students) who understand the structure of the verb "show". 


\section{The Collocates of the Verb 'Give'}

The verb of 'give' in Oxford Dictionary Thesaurus \& Wordpower Guide (2001: 378) means (1) to cause (someone) to have, get, or experience; (2) carry out (an action) or make (a sound); (3) show: he gave no sign of life; (4) put forward (information or argument); (5) have a result; (6) (give off/out) send out (a smell, heat, etc.); (7) admit that (someone) deserves recognition for (something); (8) bend under pressure.

The data shows as below.

Picture 3.3 Clusters/N-grams the verb 'give'

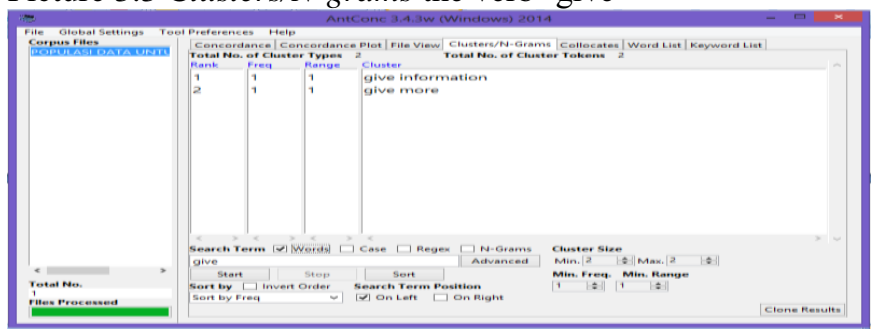

Based on the picture 3.3 above, there was only 1 student who wrote the verb 'give' with the appropriate way. This student used the collocate "information" following the verb 'give'. In the phrase of 'give more', based on the English grammar structure the usage of 'give' is supposed to be "give something more".

\section{The Collocates of the Verb 'Inform'}

The verb 'inform' based on the Oxford Dictionary (2001: 463) means (1) give facts or information to; (2) (inform on) give information about (someone's involvement in a crime) to the police. The students chose the collocates 'the' and 'you' which is described into the picture 3.4 below.

Picture 3.4 Clusters/N-grams the verb Inform

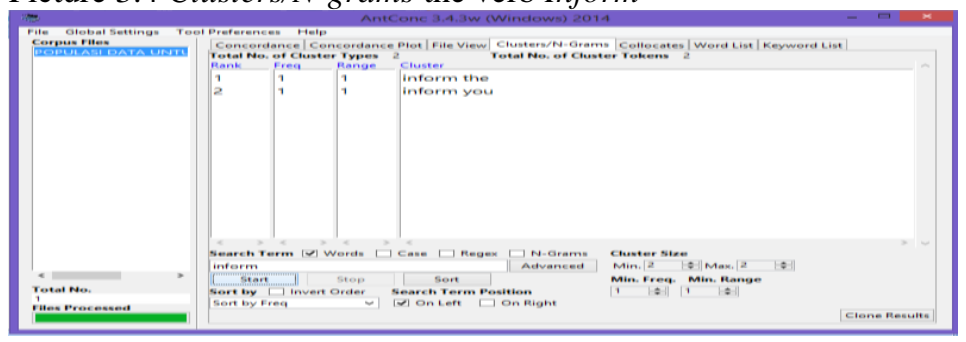

Based on the picture 3.4 above the usage of the verb 'inform' appears together with determiner 'the' (1 times) and pronoun 'you' (1 times). Those collocates chosen by students could be understood as:

(1) [We would like to] inform the [graph]

(2) [We would like to] inform you [that -clause]

This collocates was chosen by 1 student out of 53 students.

\section{The Collocates of the Verb 'Increase'}

The verb 'increase' in Oxford Dictionary (2001: 456) means "make or become greater in size, amount, or intensity". This verb is one of the keyword, since the data is about the text of graph. This graph told about selling in business. There were 5 students chose the preposition 'in', 2 students chose to use conjunction 'and', 2 other students chose preposition 'for', 2 more other students chose adverb 'slightly', another 2 students chose preposition 'to'. The rest is preposition 'over' and adverb 'especially' to be appeared with the verb 'increase'. The students choices describe in the picture below. 
Picture 3.5 Cluster/N-grams the verb Increase

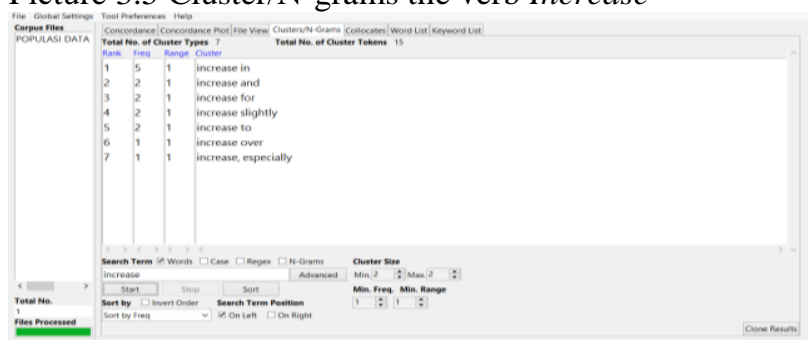

The verb 'increase' is both transitive and intransitive. As the transitive, this verb needs the object, on the other hand, as the intransitive, it doesn't need any object. In Wordnet the usage of this verb 'increase' is as follows.

(3) The amount of work increased

(4) The university increased the number of students

In number (3) the verb 'increase' is in the form of intransitive; and in number (4) the verb 'increase' is in the form of transitive since it needs the object. below.

The result of the students' writing showed that the students prefered to use preposition 'in' as can be seen

(5) There was a slight increase in amount (3 times)

(6) There was dramatically increase in third year (1 times)

(7) There were increase in amount of money (1 times)

The usage of the verb 'increase' together with the adjective 'slight' appeared 3 times which means that there were 3 students who used the same expressions. One student chose adverb 'dramatically' together with the verb 'increase'; and another student arranged the verb 'increase' into a clause.

From those analysis, it can be concluded that there were 5 students who had english language competence out of 53 students.

\section{The Collocates of the Verb 'Decrease'}

The verb 'decrease' in Oxford Dictionary and Thesaurus Wordpower Guide (2001: 224) means "to make or become a smaller or fewer in size, amount, or strength". The usage of the verb 'decrease' in Wordnet is as follows.

(8) The amount of homework decreased towards the end of the semester.

(9) He decreased his staff.

The usage of the verb 'decrease' through the students' writing result is as follows.

Picture 3.6 Cluster/N-gram the verb Decrease

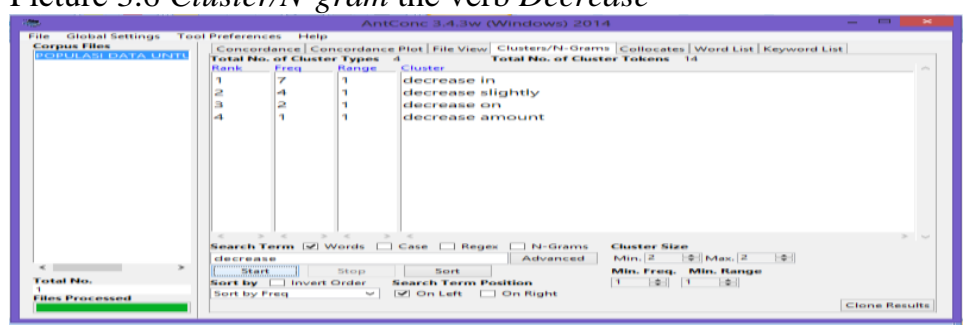

Based on the picture 3.6 above, it can be seen that students prefered to use preposition 'in' following the verb 'decrease' as much as 7 students. Let's take a look at their writing below.

(10) There was a slight decrease in amount /.../ (7 times)

Based on the corpus, there were 7 students who used exactly the same expression as it is seen in number (10); and there were 4 students who chose adverb 'slightly' occured together with the verb 'decrease' with various expressions. 


\section{The Collocates of the Verb 'Rise'}

The verb 'rise' in Oxford Dictionary and Thesaurus Wordpower Guide (2001: 776) means to come or go up; increase in number, size, strength, or quality. Based on the meaning, it is understood that the verb 'rise' has the same meaning with the word 'increase'. The usage of verb 'rise' based on Wordnet is as follows.

(11) The value of our house rose sharply last year.

(12) The stock market is going to rise.

The students frequently used the verb 'rise' collocated with preposition 'in' as it is seen from the picture below.

Picture 3.7 Cluster/N-grams the verb Rise

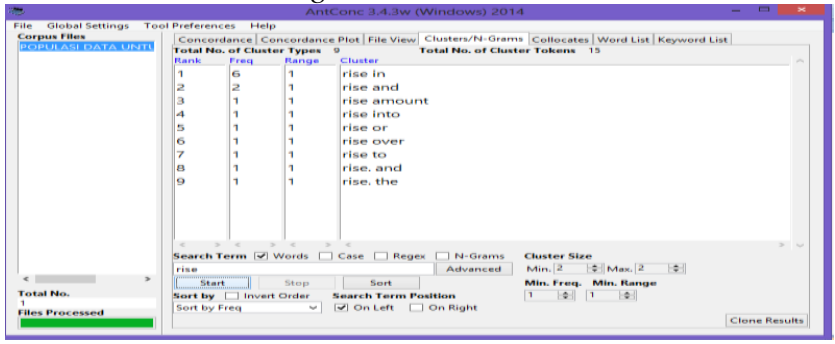

From the picture 3.7 above, it can be seen that there were 6 students who used the verb 'rise' collocated with preposition "in". Two students used the verb 'rise' followed by conjunction 'and'. Let's compare to picture 3.8 below, the students so confused in applying the word 'rise' categorized as verb with the word 'rise' categorized as noun.

Picture 3.8 Cluster/N-gram the word 'Rise' as Noun

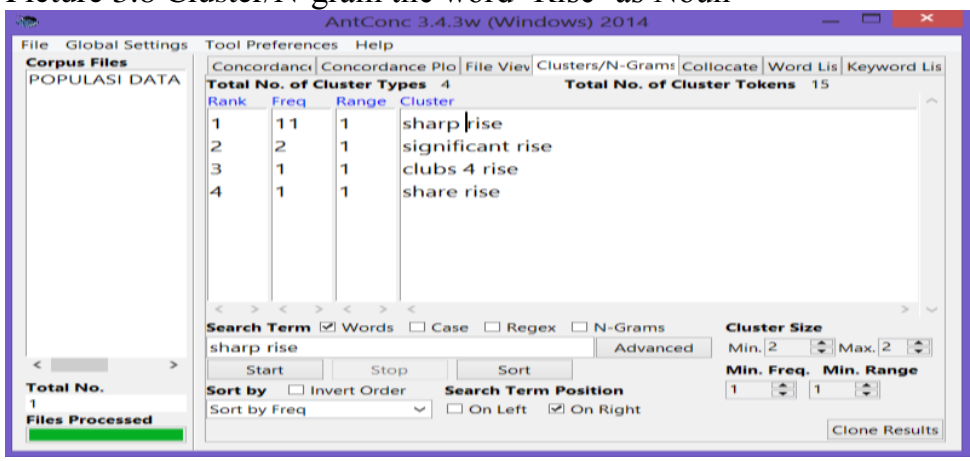

Based on the picture 3.8 above, it is seen that there were 11 students frequently used the word 'rise' as noun instead of as verb. This is understood as the word noun appeared in their writing as predicate.

\section{(13) There [are/was] [a] [sharp] [rise]}

$$
\text { S P }
$$

In this case, it can be concluded that the students could not use the verb 'rise' grammatically due to their mixing up with the predicate in Bahasa.

\section{The Collocates of the Verb ' $F$ all'}

The verb 'fall' in Oxford Dictionary and Thesaurus Wordpower Guide (2001: 320) means "move downwards quickly and without control; collapse to the ground." The usage of the verb 'fall' in Wordnet is as follows.

(14) The Branch fell from the tree.

(15) The payment fall on the 1 st of the month (be due).

(16) Fall from cloud.

(17) The cities fell to the enemy

(18) Fall into a category. 
Based on the corpus using cluster/N-gram, the students prefered to use preposition "in" following the verb 'fall'. As can be seen from the picture below.

Picture 3.9 Clusters/N-Grams the verb Fall

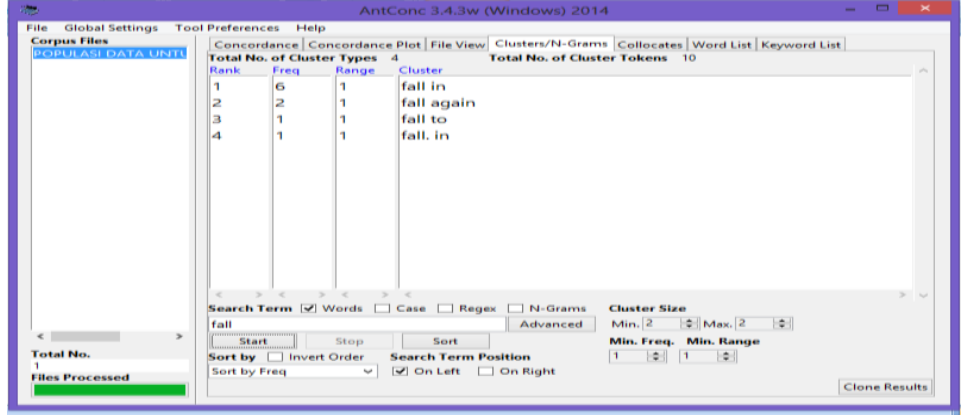

From the picture 3.9 above, it can be seen that there were 6 students who frequently used preposition "in" following the verb "fall'. If it is compared to Wordnet, the verb "fall' is followed by preposition "from", "to", "on", and "into". Based on findings in the picture, there was only 1 student who used preposition "to", which is in accord with the usage in the Wordnet (no. 17).

Based on the data and analysis above, the researcher received the picture as below.

Table 3.10 The Language Competence of the Secretary Students through Report Writing

\begin{tabular}{|l|l|l|}
\hline Verb & No. students & Percentage \\
\hline show & 6 out of 53 & $11 \%$ \\
\hline give & 1 out of 53 & $1.8 \%$ \\
\hline inform & 1 out of 53 & $1.8 \%$ \\
\hline increase & 5 out of 53 & $9.4 \%$ \\
\hline decrease & 11 out of 53 & $20.7 \%$ \\
\hline rise & 0 out of 53 & $0 \%$ \\
\hline fall & 1 out of 53 & $1.8 \%$ \\
\hline
\end{tabular}

\section{Conclusion}

Based on the analysis, it can be concluded that the language competence of the Secretary Students is very low. It can be seen from the data and analysis above which is described in the table 3.10. From the total of 53 texts, which means 53 students who conducted a report writing, there were less than $30 \%$ of the students who could give a good report writing. This is due to the lack of the English grammar structure and mix up with their nation language. It needs a concrete way to overcome this problem and also it needs an urgent works of the English instructors or lecturers to give this "Secretary to be" the treatment of how to use the English language based on pragmatic approach. So that, the students are not merely memorizing the structure but they know how to apply certain words into the sentence.

\section{References}

Biber et al. 1999. Longman Grammar of Spoken and Written English. England: Pearson Education Limited.

Citraresmana, Elvi. 2014. Fenomena Penggunaan Verba Lie dalam Korpus Amerika (COCA) Periode 1998-2012. Disertasi. Universitas Indonesia.

Kennedy, G. 1998. An Introduction to Corpus Linguistics. London: Longman.

Lindquist, Hans. 2009. Corpus Linguistics and the Description of English. Edinburgh: Edinburgh University Press. McEnery and Hardie. 1996. Corpus Linguistics: An Introduction. Edinburgh: Edinburgh University Press.

McEnery and Wilson. 2001. Corpus Linguistics: An Introduction. Second Edition. Edinburgh: Edinburgh University Press. 
McEnery and Hardie. 2012. Corpus Linguistics. Cambridge: Cambridge University Press.

Palmer, Harold E. 1933, 1966. Second Interim Report on English Collocations. Tokyo: Kaitakusha.

Sinclair et al. 2004. Trust the Text: Language, Corpus, and Discourse. London: Routledge. 